\title{
GAMBARAN TINGKAT PENGETAHUAN DAN PENGGUNAAN AMOXICILLIN DI MASYARAKAT KAMPUNG KOLEBERES RW 16 KELURAHAN DAYEUHLUHUR KECAMATAN WARUDOYONG KOTA SUKABUMI
}

\author{
Neilli Apolina CCI ${ }^{*}$, Yudi Setiawan $2^{1}$ \\ ${ }^{1}$ Program Studi D3 Farmasi, Sekolah Tinggi Teknologi Industri dan Farmasi Bogor, \\ ${ }^{2}$ Kampung Kolebere Sukabumi \\ Korespondensi: neilliacci8283@gmail.com
}

\begin{abstract}
ABSTRAK
Penggunaan amoxicillin yang tidak tepat, sering ditemukan di masyarakat, penyebab resiko resistensi antibiotik. Penelitian bertujuan mengetahui gambaran tingkat pengetahuan dan penggunaan amoxicillin di masyarakat kampung Koleberes RW 16 Kelurahan Dayeuhluhur Kecamatan Warudoyong Kota Sukabumi. Data dikumpulkan dengan teknik pengisian kuisioner yang telah divalidasi. Sampel ditentukan dengan purpose sampling berdasarkan kriteria inklusi yaitu masyarakat berusia 17-65 tahun dengan jumlah responden sebanyak 78 orang. Hasil penelitian menunjukan bahwa presentase tingkat pengetahuan responden terhadap amoxicillin, diketahui bahwa yang termasuk kedalam kategori tingkat pengetahuan baik diperoleh angka 17,9 $\%$, kategori cukup 46,2\%, dan kategori kurang 35,9\%. Sementara untuk tingkat penggunaan amoxicillin, responden yang termasuk kedalam kategori tingkat pengetahuan baik diperoleh angka $15,4 \%$, kategori cukup $43,6 \%$, dan kategori kurang $41 \%$.
\end{abstract}

\section{Kata kunci : Amoxicillin, Pengetahuan, Penggunaan}

\begin{abstract}
Inaccurate uses of amoxicillin are found in large society. It can be the cause of bad risks like antibiotic resistance. The purpose of this study was to determine the level of knowledge and use of amoxicillin in the Koleberes rw 16 community, in Dayeuhluhur Village, Warudoyong district, Sukabumi city. Data were collected using validated questionnaire filling techniques. The sample was determined by purpose sampling based on the inclusion criteria of a 17-65 year old people with 78 respondents. Research show that the percentage of respondents' knowledge level of amoxicillin, that included in the category good level of knowledge as much as $17,9 \%$, enough category as much as $46.2 \%$, and a less category as much as $35.9 \%$. While for the level of amoxicillin usage, respondents who fall into the category of good knowledge level were $15.4 \%$, category enough was $43.6 \%$, and the less category was $41 \%$.
\end{abstract}

Key word: Amoxicillin, Knowledge, Use

\section{PENDAHULUAN}

Antibiotik merupakan jenis obat yang dipakai untuk mengobati berbagai jenis infeksi akibat kuman. Antibiotik bekerja dengan cara membunuh bakteri atau mencegahnya bereproduksi dan menyebar pada manusia (WHO, 2018). Antibiotik digolongkan ke dalam golongan obat keras yang tersedia di apotek (BPOM, 2015).

Data Riskesdas pada tahun 2013, menyatakan 35,2\% dari 294.959 masyarakat menggunakan obat untuk pengobatan sendiri. Dari $35,2 \%$ masyarakat tersebut, $27,8 \%$ menggunakan obat antibiotik, dan $86,1 \%$ didapatkan tanpa menggunakan resep dari dokter. Berdasarkan Pedoman Umum Penggunaan Antibiotik, pada masyarakat yang tidak tepat menyebabkan risiko keamanan pasien, menimbulkan ketidakefektifan dalam pengobatan, tingginya biaya pengobatan, dan menyebarnya kasus resistensi (Kemenkes RI, 2011).

Berdasarkan penelitian yang dilaksanakan di Yogyakarta 7\% masyarakat memakai antibiotik untuk pengobatan sendiri. Antibiotik amoxisilin merupakan antibiotik terbanyak 
dibeli tanpa resep dokter atau sebesar (77\%) selain ampicillin, tetracycline dan siprofloksasin. rata-rata obat - obat tersebut dipakai dalam rangka mengobati sakit flu, batuk, tenggorokan, pusing, dan beberapa sakit ringan lain, dan biasanya digunakan selama lima hari (Widayati 2011). Selain itu, berdasarkan penelitian di Probolinggo, Salah satu jenis antibiotik yang sering digunakan tanpa menggunakan resep dokter yaitu Amoxillin atau sebesar (64\%). Berdasarkan dari segi keuangan $60 \%$ menjawab bahwa membeli antibiotik tanpa resep dokter lebih murah, dan $40 \%$ menjawab karena kemauan sendiri untuk menggunakan obat tanpa konsultasi ke dokter (Kurniawati, 2019)

Hasil penelitian sebelumnya menunjukkan bahwa perilaku sikap yang positif dan baik pada seorang individu dipengaruhi oleh pengetahuan yang baik. Sikap dan perilaku penggunaan antibiotik yang tepat berhubungan dengan penurunan risiko kejadian resistensi (Awad dan Aboud, 2015).

Kelurahan Dayeuhluhur adalah tempat di dekat sarana kesehatan seperti apotek dan puskesmas. RW 16 di Kampung Koleberes merupakan tempat yang paling dekat terhadap sarana kesehatan tersebut. Penulis berkeinginan untuk melakukan penelitian dengan tujuan untuk mengetahui "Gambaran tingkat pengetahuan dan penggunaan amoxicillin di masyarakat kampung Koleberes RW 16 Kelurahan Dayeuhluhur Kecamatan Warudoyong Kota Sukabumi”.

\section{METODE PENELITIAN}

Penelitian non eksperimental dengan metode survey deskritif kuantitatif menggunakan kuesioner. Dengan data yang dikumpulkan secara prospektif. Pendekatan dilakukan secara crosectional, sampel ditentukan dengan menggunakan metode purposive sampling

Kriteria inklusi Responden dengan kelompok umur 17 sampai 65 tahun. dan Responden yang pernah menggunakan amoxicillin. bulan Januari - Juni 2020

Teknik pengumpulan data dengan metode wawancara terpimpin dilakukan pengisian kuesioner sesuai tujuan penelitian.

\section{HASIL DAN PEMBAHASAN}

Responden memiliki karakteristik usia, jenis kelamin, pendidikan, dan jenis pekerjaan. Data yang diperoleh adalah :

Tabel 1. Persentase tingkat pengetahuan berdasarkan usia.

\begin{tabular}{cccc}
\hline Usia & \multicolumn{3}{c}{ Tingkat Pengetahuan } \\
\cline { 2 - 4 } & Baik (\%) & Cukup (\%) & Kurang (\%) \\
\hline $17-25$ & 0 & 63,6 & 36,4 \\
\hline $26-35$ & 12,5 & 54,2 & 33,3 \\
\hline $36-45$ & 25 & 50 & 25 \\
\hline $46-55$ & 25 & 43,8 & 31,2 \\
\hline $56-65$ & 0 & 33,3 & 66,7 \\
\hline
\end{tabular}

Tabel 2. Persentase tingkat pengetahuan berdasarkan pendidikan

\begin{tabular}{cccc}
\hline \multirow{2}{*}{ Pendidikan } & \multicolumn{3}{c}{ Tingkat Pengetahuan } \\
\cline { 2 - 4 } & Baik (\%) & Cukup (\%) & Kurang (\%) \\
\hline SD / Sederajat & 8,3 & 41,7 & 50 \\
\hline SMP / Sederajat & 0 & 60 & 40 \\
\hline SMA/ Sederajat & 12,8 & 51,3 & 35,9 \\
\hline Diploma / Sarjana & 58,4 & 33,3 & 8,3 \\
\hline
\end{tabular}


Tabel 3. Persentase tingkat pengetahuan berdasarkan jenis pekerjaan

\begin{tabular}{lccc}
\hline Jenis & \multicolumn{3}{c}{ Tingkat Pengetahuan } \\
\cline { 2 - 4 } Pekerjaan & Baik (\%) & Cukup (\%) & Kurang (\%) \\
\hline Wiraswasta & 0 & 56,2 & 43,8 \\
\hline Swasta & 25,3 & 52,9 & 11,8 \\
\hline Buruh & 0 & 45,5 & 54,5 \\
\hline IRT & 17,9 & 46,4 & 35,7 \\
\hline PNS/lainnya & 33,3 & 50 & 16,7 \\
\hline
\end{tabular}

Tabel 4. Persentase tingkat pengetahuan berdasarkan jenis kelamin.

\begin{tabular}{cccc}
\hline Jenis Kelamin & \multicolumn{3}{c}{ Tingkat Penegtahuan } \\
& Baik (\%) & Cukup (\%) & Kurang (\%) \\
Pria & 11,7 & 41,2 & 47,1 \\
Wanita & 22,7 & 50 & 27,3 \\
\hline
\end{tabular}

Tabel 5. Distribusi frekuensi informasi yang didapat mengenai amoxicillin

\begin{tabular}{lll}
\hline Sumber Informasi & Frekuensi & Presentasi $(\%)$ \\
\hline Dokter & 69 & 88,5 \\
\hline Kerabat/Sahabat & 9 & 11,5 \\
\hline Jumlah & 78 & 100 \\
\hline
\end{tabular}

Dengan usia yang semakin dewasa, maka kedewasaan seseorang akan lebih baik dan tingkat kepercayaan semakin tinggi (Nursalam, 2011). Pada kelompok 36 - 45 tahun dan kelompok 46 - 55 tahun masuk dalam kategori baik dengan persentase paling tinggi yaitu 25 $\%$, dan kelompok umur 56 - 65 tahun masuk kedalam kategori kurang dengan persentase paling tinggi, yakni sebesar 66,7\% (tabel 1), hal ini sesuai dengan Saparinah dalam Yeremia (2019) dimana lansia akhir adalah usia tahap praenisium, mengalami berbagai penurunan daya tahan tubuh dan tekanan psikologis.

Pendidikan yang semakin tinggi, semakin banyak pengetahuan (Nusalam, 2011) Tapi masih ditemukan responden dengan tingkat pendidikan diploma / sarjana masuk ke dalam kategori kurang (tabel 2) Menurut Lina (2015) Peningkatan pengetahuan diperoleh selain dari pendidikan formal, juga dari non formal. Informasi mengenai pengobatan khususnya antibiotik diperoleh pada pendidikan kesehatan. atau dari tenaga medis.

Data dari data tabel 3 tentang distribusi frekuensi berdasarkan pekerjaan, menurut Notoatmodjo (2010) pekerjaan seseorang akan mempengaruhi proses dalam mencari informasi, sehingga pengetahuan juga semakin meningkat.
Data dari data tabel 4 tentang distribusi frekuensi tingkat pengetahuan berdasarkan jenis kelamin diperoleh hasil pengumpulan data bahwa responden dengan jenis kelamin laki laki masuk dalam kategori baik 11,7 \%, kategori cukup sebanyak 41,2 \%, dan kategori kurang sebanyak $47,1 \%$. Responden dengan jenis kelamin perempuan masuk dalam kategori baik 22,7\%, kategori cukup $50 \%$, dan kategori kurang $27,3 \%$. Jenis kelamin perempuan termasuk kedalam kategori baik dengan persentase paling tinggi, yakni $22,7 \%$. wanita lebih mempedulikan kesehatan dan memiliki pengetahuan yang lebih baik mengenai pengobatan (Rasmi 2018)

Dalam penelitian ini mayoritas responden mendapatkan informasi mengenai amoxillim dari dokter sebanyak $88,5 \%$, dan masih terdapat responden yang mendapatkan informasi mengenai amoxicillin dari kerabat / sahabat yaitu sebesar 11,5\% (tabel 5). Seseorang yang memperoleh informasi maka tingkat pengetahuan terhadap suatu hal akan lebih meningkat (Nursalam 2010). 
Gambar 1. Diagram Tingkat Pengetahuan Responden Tentang Amoxicillin.

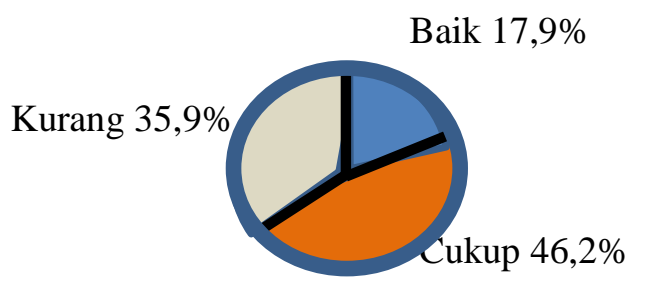

$\square$ Baik $\square$ Cukup $\square$ Kurang

Berdasarkan Tingkat Pengetahuan Responden Tentang Amoxicillin diketahui bahwa responden masuk kedalam kategori tingkat pengetahuan baik $17,9 \%$, kategori cukup 46,2\% (tertinggi), dan kategori kurang $35,9 \%$.

\section{Gambar 2 Diagram Tingkat Penggunaan Amoxicillin}

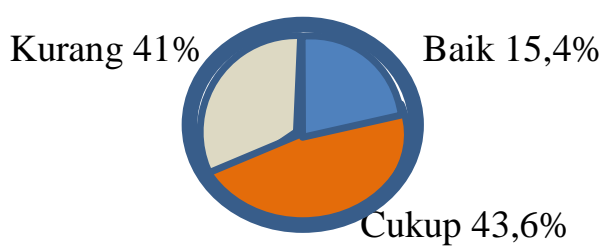

Baik

$\square$ cukup $\square$ kurang

\section{DAFTAR PUSTAKA}

[1] Awad, A. I. dan Aboud, E. A. 2015. Knowledge, Attitude and Practice [1] towards Antibiotic Use among the Public in Kuwait. PLoS ONE. Dalam: A. C. Singer (Editor). Public Library of Science. 10(2)

[2] Arikunto. 2010. Prosedur Penelitian Suatu Pendekatan Praktik. Jakarta : Penerbit Rineka Cipta

[3] Andarwati, R. 2014. Gambaran Pengetahuan dan Sikap Ibu Rumah Tangga terhadap Penggunaan Antibiotik di Desa Kuta Mbelin Kecamatan Lau Baleng Kabupaten Karo.

Jurnal Ilmiah PANNMED. 9(2): 111-
Tingkat Penggunaan Amoxicillin Berdasarkan gambar 2 diatas diketahui bahwa responden yang termasuk kedalam kategori tingkat pengetahuan baik 15,4\%, kategori cukup $43,6 \%$, dan kategori kurang $41 \%$. Data diatas menunjukan bahwa mayoritas responden masuk dalam kategori cukup. Hasil tersebut disebabkan bahwa masih ditemukan banyak kesalahan dalam penggunaan amoxicillin, seperti dalam waktu pemberian dan frekuensi konsumsi.

Ditemukan mayoritas responden beranggapan bahwa amoxicillin boleh digunakan hanya satu tablet jika diperlukan. Amoxicillin sendiri termasuk kedalam antibiotik golongan penisilin, dimana penggunaannya harus sampai tuntas sesuai anjuran dokter. Selain itu ditemukan mayoritas responden beranggapan bahwa penggunaan amoxicillin dengan dosis sehari tiga kali satu tablet diminum pagi, siang dan sore. Antibiotik dengan aturan pakai 3 kali sehari diartikan diminum dengan interval waktu setiap delapan jam (kemenkes, 2011).

\section{SIMPULAN}

Berdasarkan penelitian yang dilakukan dapat diketahui gambaran tingkat pengetahuan dan penggunaan amoxicillin mayoritas termasuk dalam kategori cukup.

118.

[5] BPOM. 2015. Pedoman Umum, (http://pionas.pom.go.id, diakses $18 \mathrm{mei}$ 2020).

[6] Grigoryan, L., Monnet, D. L., HaaijerRuskamp, F. M., Bonten, M. J., Lundborg, S., dan Verheij, T. J. 2010. Self-medication with antibiotics in Europe: a case for action. Current drug safety. Bentham Science Publishers. 5(4): 329- 332.

[7] Ihsan, S; Kartika dan Aki, N.I. 2016. Studi Penggunaan Antibiotik Non Resep di Apotek Komunitas Kota Kendari. Media Farmasi. Volume 13 Nomor 2.

[8] International Journal of Pharmacy and Pharmaceutical Sciences Vol 3 (3): 30- 
52 Neilli Apolina CCI et al., (Gambaran Tingkat Pengetahuan Dan Penggunaan ...)

37.

[9] Juwita, D.A: Arifin, H. dan Yulianti, N 2017. Kajian Deskriptif Restrospektif Regimen Dosis Antibiotik Pasien Pneumia Anak di RSUP. Dr. M. Djamil Padang. Jurusan Sains Farmasi Dan Klinis. Volume 3 Nomor 2.

[10] Kaur, Simar Preet., Rekha Rao, dan Sanju Nanda. 2011. Amoxicillin: A Broad Spectrum Antibiotic

[11] Kementerian Kesehatan, RI. 2011 "Modul Penggunaan Obat Rasional", Jakarta, Indonesia.

[12] Kementerian Kesehatan RI, 2011. Pedoman Umum Penggunaan Antibiotik. Jakarta: Kementerian Kesehatan RI

[13] Kementerian Kesehatan, RI. 2013. "Riset kesehatan dasar", Badan Penelitian dan Pengembangan Kesehatan Departemen Kesehatan Republik Indonesia, Jakarta, Indonesia

[14] Kementerian Kesehatan, RI. 2016. "Warta Yankes", Jakarta, Indonesia

[15] Kurniawati. 2019. Gambaran penggunaan antibiotik tanpa resep dokter oleh konsumen di apotek $\mathrm{x}$ wilayah Probolinggo.

[16] Laili. 2019. Hubungan Pengetahuan Masyarakat Terhadap Prilaku Penggunaan Antibiotik.

[17] Lina, 2015. Gambaran Tingkat Pengetahuan Masyarakat Tentang Antibiotik dan Penggunaannya di Puskesmas Sindangjaya Kota Bandung.

[18] Liwang, Debby Permatasari. 2017. Evaluasi Rasionalitas Penggunaan Antibiotik Pasien Ulkus Kaki Diabetika Yang Menjalani Rawat Inap di Rumah Sakit Panti Rini Yogyakarta Periode 2015-2016. Skripsi. Yogyakarta: Universitas Sanata Dharma

[19] Notoatmodjo, Soekidjo. 2014. Ilmu Perilaku Kesehatan. Jakarta: Rineka Cipta

[20] Notoatmodjo, Soekidjo. 2010. Metodologi Penelitian Kesehatan. Jakarta: Rineka Cipta.

[21] Nursalam. 2011. Konsep dan Penerapan
Metodologi Penelitian Ilmu Keperawatan. Salemba Medika: Jakarta

[22] O’Neill, J. 2014. Antimicrobial resistance: tackling a crisis for the future health and wealth of nations, the review on antimicrobial resistance, (http://www.jpiamr.eu, diakses 16 Juli 2018)

[13] Rasmi, 2018. Hubungan Pengetahuan Keluarga dengan Penggunaan Obat Tradisional di Desa Nunggalrejo Kecamatan Punggur Kabupaten Lampung Tenga

[14] Riberu, Vinsesius. 2018. Tingkat Pengetahuan Masyarakat Tentang Penggunaan Antibiotik di Desa Woe Kecamatan Wewiku Kabupaten Malaka

[15] Rusuli, I. dan Daud, Z. F. M. 2015. Ilmu pengetahuan dari John Locke ke alAttas. Jurnal Pencerahan. 9(1)

[16] Sugiyono, 2014. Statistika untuk Penelitian, Bandung: Alfabeta.

[17] Utami, Eka Rahayu. 2012. Antibiotk, Resisten, dan Rasionalitas Terapi. Saintis. Volume 1 Nomor 1

[18] World Health Organization. 2018. Antibiotic Resistance, (http://www.who.int, diakses 17 mei 2020)

[19] World Health Organization. 2018. Antimicrobial Resistance, (http://www.who.int, diakses Juni 2020).

[20] Widayati A, Suryawati., Crespgny C., Hiller J.E., 2011. Self Medication with Antibiotic in Yogyakarta City Indonesia: A Cross Sectional Population Basedsurvey. BMC research notes. 4 (491): 1

[21] Yeremia, 2019. Gambaran Kemandirian Pada Lansia 